\title{
Turkish Adaptation of ACTIVLIM Questionnaire in Neuromuscular Diseases by Rasch Analysis
}

\author{
ACTIVLIM Ölçeği'nin Rasch Analizi ile Nöromusküler Hastalıklarda Türkçe Adaptasyonu
}

\author{
Muhammed KILINÇ ${ }^{1}$, Çiğdem ÖKSÜZ ${ }^{2}$, Derya GÖKMEN ${ }^{3}$, İpek GÜRBÜZ ${ }^{1}$, Cevher \\ DEMIRCi ${ }^{4}$, Hatice ABAOĞLU ${ }^{5}$, Sibel AKSU YILDIRIM ${ }^{6}$, Öznur TUNCA YILMAZ \\ ${ }_{1}^{1} \mathrm{PhD}$, Assoc. Prof., Hacettepe University, Faculty of Health Sciences, Department of Physiotherapy and Rehabilitation Ankara, Turkey \\ ${ }^{2} \mathrm{PhD}$, Prof., Hacettepe University, Faculty of Health Sciences, Occupational Therapy Department Ankara, Turkey \\ ${ }^{3} \mathrm{PhD}$, Assoc. Prof., Ankara University Faculty of Medicine Department of Biostatistics Ankara, Turkey \\ ${ }^{4} \mathrm{PhD}$, Assoc. Prof., Kırıkkale University, Faculty of Health Sciences, Department of Physiotherapy and Rehabilitation Kırıkkale, Turkey \\ ${ }^{5} \mathrm{PhD}$, Hacettepe University, Faculty of Health Sciences, Occupational Therapy Department Ankara, Turkey \\ ${ }^{6}$ PhD, Prof., Hacettepe University, Faculty of Health Sciences, Department of Physiotherapy and Rehabilitation Ankara,Turkey
}

\section{ABSTRACT}

Purpose: The aim of this study was to assess the reliability and validity of the ACTIVLIM questionnaire for Turkish-speaking neuromuscular disease (NMD) patients with the Rasch analysis. Material and Methods: 169 NMD patients were included in the study. The independence level regarding activities of daily living was assessed using the Functional Independence Measurement (FIM) scale while activity limitation was evaluated with the Activlim questionnaire. All assessments were performed twice, at the beginning of the study and 15 days later. Statistical analysis was done by using Rasch method. Results: 95 children with a median age of 10 and 74 adults with a median age of 34.5 years were included in the study. Seventy patients $(41.7 \%)$ were assessed a second time. Starting with 22 items, one item (ACTIVLIM 5- Sitting on the toilet) displayed disordered thresholds, necessitating collapsing of categories. According to test/retest reliability, none of the items showed differential item functioning. Internal consistency of the scale is sufficent (Cronbach's alpha 0.94). The scale showed expected correlation with FIM scores (Pearson 0.95) which revealed external construct validity of the scale. Discussion: ACTIVLIM is found as a reliable and valid questionnaire that can be used in the Turkish NMD population to assess activity limitation.

Key Words: Neuromuscular diseases; Reliability and validity; Activities of daily living

\section{öz}

Amaç: Bu çalışmanın amacı, Türkçe konuşan nöromüsküler hastalığı (NMH) olan bireylerde ACTIVLıM Ölçeği'nin Rasch analizi ile güvenirlik ve geçerliğini değerlendirmektir. Gereç ve Yöntem: Çalışmaya 169 $\mathrm{NMH}$ hastası dahil edildi. Günlük yaşam aktiviteleri ile ilgili bağımsızlık düzeyi Fonksiyonel Bağımsızlık Ölçeği, aktivite kısıtlaması ACTIVLıM Ölçeği kulanılarak değerlendirildi. Değerlendirmeler, çalışmanın başında ve 15 gün sonra olmak üzere iki kez yapıldı. İstatistiksel analiz Rasch yöntemi kullanılarak yapıldı. Sonuçlar: Çalışmaya, ortanca yaşı 10 olan 95 çocuk ve ortanca yaşı 34,5 olan 74 yetişkin dahil edildi. Yetmiş hasta (\% 41,7) ikinci kez değerlendirildi. 22 maddeden ile başlanmış olup, bir maddeye (ACTIVLIM 5- Tuvalette oturma) ilişkin eşik değerleri, ölçek kategorileri ile uyumsuzluk gösterecek şekilde sıra takip etmedi. Test / tekrar test güvenirliğine göre, maddelerden hiçbiri madde işlev farklılığı göstermedi. Ölçeğin iç tutarlıı̆̆ı yeterlidir (Cronbach'ın alfa 0,94). Ölçek, dış yapı geçerliliğini oluşturan FBÖ puanları ile beklenen korelasyonu göstermiştir (Pearson 0,95). Tartışma: ACTIVLIM, Türk NMH popülasyonunda aktivite kısıtıııklarını değerlendirmek için kullanılabilecek güvenilir ve geçerli bir anket olarak bulunmuştur.

Anahtar Kelimeler: Nöromüsküler hastalıklar; Güvenilirlik ve geçerlilik; Günlük yaşam aktiviteleri.

Corresponding Author (Sorumlu Yazar): Hatice Abaoğlu E-mail: haticeabaoglu@hacettepe.edu.tr ORCID ID: 0000-0001-8060-3730

Received (Geliş Tarihi): 27.03.2019; Accepted (Kabul Tarihi): 04.09.2019

The abstract of this study was presented as a poster in 18th International Congress of the World Muscle Society, California, USA, 1th5th October 2013. 
Patients with neuromuscular disease (NMD); can experience muscle weakness, limitation of activities of daily living (ADL) and restriction of social, work and family participation as a result of the progressive feature of the disease (Oksuz, Akel and Bumin, 2011). Patients may have different functional capacity although having the same muscle strength level, due to their targets, priorities and expectations (Berard, Payan, Hodgkinson et al, 2005). It is accepted that 'activity limitation and participation are the most appropriate aspects of the disease for measurement' in chronic diseases such as NMD (Merkies and Hughes, 2010). The clinician needs to measure disability, activity limitation and participation restrictions to develop an optimal treatment programme, to monitor the effectiveness of the programme and to evaluate the progression of the disease. Measurement of activity limitation has a key role that shows the negative effects of the disease on the patient. The clinician must therefore evaluate the activity level completely and accurately (Vandervelde, Van den Dergh, Goemans et al, 2007).

Timed performance tests, ADL tests, disease specific functional tests and functional state questionnaires are often used in clinical practice to assess activity level of NMD patients (Nair, Vasanth, Gourie-Devi et al, 2001). However, there are some disadvantages of these tests. These instruments mostly focus on observed test behavior. For example, the timed performance tests focus on endurance and the velocity of the activity but not the quality. FIM is the preferred method to assess ADL but measures the independence of the patient by taking into account environmental factors. The 'Barthel Index' is short and simple to apply, so it is usually used in the acute services of hospitals. The 'Brooke Upper Extremity Scale' is generally preferred for pediatric NMD (Vandervelde et al, 2007; Torres, Moxley and Griggs, 1983). All these tests neglect the opinion of the patient regarding the disease or selected activity. On the other hand, self-reported outcome measurements have become a common instrument in rehabilitation settings to assess the patients' perception of their health, and the impact of the disorder on their life as a tool for determining treatment (Emery, Perrier and Acquadro, 2005).

The ACTIVLIM developed by Vandervelde is a 'self-reported questionnaire of activity limitations in children and adults with all types of NMD, and evaluates activity limitations in terms of difficulties in performing daily activities without technical or human assistance'. The scale is one of the comprehensive, non-disease specific assessment tool for NMD (Raggi and Leonardi, 2009). This feature of the test is important to compare the activity capacities of the many types of NMD (there are nearly 600 different kinds of NMD) (Cup, Pieterse, ten Broek Pastoor et al, 2007). Besides, ACTIVLIM makes it possible to follow the course of the disease in a patient from childhood to adulthood when necessary, for example in Becker muscular dystrophy (Raggi et al, 2009).

Traditional statistical methods are widely used to determine scale reliability and validity. However, they have important limitations for evaluating the measurement properties of rating scales. (Mayhew, Cano, Scott et al, 2011). Hobart and colleagues compared the responsiveness of the FIM and Barthel scale results of 976 people by using Rasch analyses. Traditional methods failed to show a significant effect but Rasch analysis revealed that $50 \%$ of the patients had a significant improvement on FIM and $31 \%$ on the Barthel index (Berard et al, 2005; Hobart, Cano and Thompson, 2010). The Rasch model shows 'what should be expected in response to an item if interval scale measurement is to be achieved. It compares the item response patterns of individuals to the entire sample to estimate the personal ability and item difficulty and places both item and person estimates on the same logit scale' (Hermans, Faber, De Baets et al, 2010). Patient-reported outcomes are frequently used for evaluation in clinical trials, where valid change scores and access to parametric statistics are required. Rasch analysis can support this process by providing a transformation of an ordinal score into a linear, interval-level variable, given fit of data to Rasch model expectations (Tennant and Conaghan, 2007). Rasch models produce interval scaled person ability estimates that are independent of the distribution of the population, and item difficulty estimates that are independent of the ability of the person (Andrich, 1988).

There is no validated measure available for the assessment of activity limitation in the Turkish NMD population, and the Activlim questionnaire was chosen for this purpose. The aim of the study was to determine the reliability and validity of the Activlim questionnaire for Turkish speaking NMD patients, by using Rasch analysis.

\section{MATERIAL AND METHODS}

This study was conducted at Hacettepe University, Department of Physiotherapy and Rehabilitation, Neurological rehabilitation outpatient unit between May 2012- May 2014 after being approved by the local ethic committee (HEK 09/271). All the 
participants signed the informed consent for the study. The patients included in the study were composed of those who had been diagnosed with a NMD at least 6 months before. Patients who suffered from any additional acute orthopedic or neurological disorder within the last one month were excluded from the study. Adult patients and parents who were literate, not hindered by any communication problem, and whose native language was Turkish, were included on a voluntary basis. A total of 169 patients (95 children aged 6 - 17 years and 74 adults aged 18 - 77 years) diagnosed as NMD were assessed by two experienced examiners $(n=95$ children for examiner 1 and $n=74$ adults for examiner 2). Demographic features (age, gender, type of NMD and disease duration) were noted at the beginning of the study.

The adaptation process of Activlim questionnaire for the Turkish population was complemented by following the guideline provided by Beaton et al (Beaton, Bomberdier, Guillemin et al, 2000). According to the process, the Activlim questionnaire was translated into Turkish by two different and independent native Turkish translator. Both translations were compared for inconsistencies. Then, the scale was re-translated blindly and independently into English by two native English translators. Each of the English translations was compared with the original English Activlim questionnaire and checked for inconsistencies. The Turkish version was then jointly reviewed by a bilingual team to determine whether cultural adaptation was required and to fine-tune it in order to use it for Turkish patients. Finally, both the Turkish and English versions were compared to find errors and then the final correction of the Turkish version was made. Permission to adapt the original version of ACTIVLIM was obtained from the developers of the questionnaire.

A second evaluation (Retest) was reimplemented 15 days after the first evaluation (Test) by the same examiner in order to evaluate the test/retest reliability of the scale.

The independence level of ADL was measured using the FIM instrument for the patients' age between 9-77. FIM consists of 18 items as self-care, sphincter control, mobility, locomotion, communication and social integration parameters. Each person's level of independence for a particular FIM item is usually rated by patient by using a 7-point Likert scale (1, total assistance is needed; 7 , complete independence). FIM motor scale score, incorporating the self-care, sphincter control, mobility, and locomotion items was used in our study to measure the independence level of the patients. FIM motor scores range from 13 to 91 . FIM is potentially a useful instrument for describing disabilities in persons with NMD and it was adapted for the Turkish language and found to be reliable and valid (Jensen, Abresch and Carter, 2005; Küçükdeveci, Yavuzer, Elhan et al, 2001).

Turkish version of Wee-Functional Independence Measure (WeeFIM) was used to measure the independence level functional abilities in children ages 6 to 7 years. It is administered by interview of a primary caregiver (parent or teacher) who knows the child well (Aybay, Erkin, Elhan et al, 2007).

Activity limitation of the patients was evaluated with the Activlim questionnaire. ACTIVLIM is a set of 22 self-administered questions of which 4 are for children, 4 are for adults and 14 are for both adults and children. Patients (age 16-77) or the parents for the children (age 6-15) have to choose their performance for each activity using a three-level response category: (0) impossible, (1) difficult and (2) easy. The patients have to be able to perform each activity without human or technical assistance (Vandervelde et al, 2008; Raggi et al, 2009; Vandervelde, Van den Gergh, Renders et al, 2009).

All assessments were done twice, at the beginning of the study and 15 days later to test the test/retest reliability for some patients. It was assumed that the clinical status did not change during this period.

Responses of the parents and adult patients should form a single matrix to calibrate a common scale for both children and adults with ACTIVLIM. The four items specifically designed for adults were recorded as a missing response in the data of the parents of the affected children. Similarly, the four specific items for children were recorded as a missing response in the data of the adult patients. The final data matrix, therefore, included 22 items (14 common, 4 children specific and 4 adult specific items).

\section{Statistical Analysis}

The psychometric properties of ACTIVLIM were evaluated through a range of analyses. This includes tests for validity and reliability.

The internal construct validity of ACTIVLIM was examined by using the Rasch measurement model (Fisher, 1993). Internal construct validity in the current study was assessed by the fit of the data to the Rasch model. The Rasch analysis includes the following sequential steps (Elhan, Oztuna, Kutlay et 
al, 2008):

1. Rescoring of ACTIVLIM items that demonstrate 'disordered thresholds'.

Items showing 'disordered thresholds' were identified from the threshold map. Disordered thresholds were corrected by collapsing adjacent response categories for the problematic items.

2. Deletion of the misfitting items.

3. Re-analysis for overall model and individual item fit.

After all items showed orderly thresholds, individual items were deleted one at a time and overall fit was reexamined after each item deletion. Fit was determined by a number of fit statistics. At the scale level, summary fit statistics included item- and person-residuals that, with perfect fit, would have a mean of zero and a standard deviation of 1 . A chisquare interaction fit statistic should be nonsignificant to show lack of deviation from model expectations. At the individual item level, fit residuals should be between \pm 2.5 ; and chi square statistics should be nonsignificant ( $>0.05$ Bonferroni adjusted). 4. Examination for differential item functioning (DIF) for gender and patient category.

DIF, examined for gender (Male/Female) and patient category (Child/Adult) should show nonsignificant differences between groups (Bonferroni adjusted).

5. Test for unidimensionality.

The sample was divided into class intervals. The degree of similarity between the observed responses in each class interval and the expected responses predicted by the model for each item were computed through a standardized residual and a $\square 2$ fit statistic.

6. Examination of local dependency.

This assumption was tested by inspection of the residual correlation matrix. If a pair of items had a residual correlation of 0.30 or more, one of the items that showed higher accumulated residual correlation with the remaining items was eliminated.

The reliability of the ACTIVLIM was examined by both internal consistency and test-retest reliability. An estimate of the internal consistency reliability of the ACTIVLIM was tested by the Person Separation Index (PSI) (Cronbach, 1951). This is equivalent to Cronbach's alpha (Fisher, 1992) but has a linear transformation from the Rasch model. For test/retest reliability of ACTIVLIM, DIF was used to verify the invariance of item difficulty hierarchy across the first and the second assessment (DIF by time). The external construct validity of the ACTIVLIM was assessed through convergent validity with the FIM total and its subscale scores. The degree of associations was analyzed by a Pearson correlation coefficient. The coefficient correlations greater than 0.6 , from $0.6-0.3$, and less than 0.3 were considered strong, moderate, and low, respectively. Data were analyzed using the Rasch-Model Computer program RUMM2020 (Rumm Laboratory Pty Ltd., Perth, Australia) (Andrich, Lyne, Sheridan et al, 2004).

\section{RESULTS}

Forward and back translation of the Activlim questionnaire revealed no major problems or language difficulties. Only item 5 (ACTIVLIM 5Sitting on the toilet) activity is defined in a different manner. In Turkey toileting is a kind of activity that can be different from European culture. In some parts of Turkey squat toilet "known also as Arabic or Turkish toilet" is a toilet used by squatting, rather than sitting is still used. So in this case the phrase "sitting on a toilet" could be understand as squatting toilet by the patients. But according to our clinical experience because of the muscle strength loss it is most of the time impossible for the patients to use squatting toilet. So in the Turkish version of the ACTIVLIM questionnaire the phrase "sitting on a toilet "is changed as "sitting on a closet toilet".

We included 95 children with a median (range) age of 10 (6-17) and 74 adults with a median (range) age of $34.5(18-77)$ years in the study. Seventy patients $(41.7 \%)$ were assessed a second time two weeks after the first evaluation in order to investigate the test-retest reliability of the scale. The median (range) of duration of symptoms was 5 (1-14) years for the children and 4 (1-25) years for the adults. The majority of the children had Duchenne muscular dystrophy (DMD) $(60.2 \%)$ and most of the adults amyotrophic lateral sclerosis (ALS) $(24.4 \%)$. The demographic characteristics of the study sample are presented in Table 1 and the FIM and WeeFIM scores are shown in Table 2.

Internal Construct Validity (Rasch Analysis), starting with 22 items, one item (ACTIVLIM 5- Sitting on the toilet) displayed disordered thresholds, necessitating collapsing of categories. Afterwards, all items were found to fit the model (given a Bonferroni adjustment fit level of 0.002) (Table 3). Overall mean item fit residual was -0.285 (SD 1.142) and mean person fit residual was -0.365 (SD 0.907). Item-trait interaction was nonsignificant, supporting the invariance of items [chi-square $30.2 \quad(\mathrm{df}=22)$, $\mathrm{p}=0.114]$. 
Table 1. Demographic Characteristics of the Patients

\begin{tabular}{lcc}
\hline & Children (n=95) & Adult $(\mathbf{n}=\mathbf{7 4})$ \\
\hline Age (Median(Range)) [Years] & $10(6-17)$ & $34.5(18-77)$ \\
Gender & & 36 \\
Male & 79 & 38 \\
Female & 16 & \\
Diagnosis (\%) & & 24.4 \\
DMD & 60.2 & 8.1 \\
ALS & & 11.1 \\
LGMD & 8.6 & 4.8 \\
Neuropathy & 6.2 & 32.6 \\
HSMN & 6.5 & 9.5 \\
Myopathy & 9.8 & 5.4 \\
Muscular Dustrophy & 6.5 & 4.1 \\
BMD & 2.2 & $4(1-25)$ \\
Others & & \\
Disease Duration (Median (Range)) [Years] & $5(1-14)$ & \\
\hline
\end{tabular}

DMD: Duchenne Muscular Dystrophy, ALS: Amyotrophic Lateral Sclerosis, LGMD:Limb-Girdle Muscular Dystrophy, HSMN: Hereditary Sensory Motor Neuropathy, BMD: Becker Muscular Dystrophy.

Table 2. FIM and weeFIM Scores of the Patients.

\section{Children}

(5-8 YEARS)
Adults

(9-77 YEARS)

\begin{tabular}{lcccc}
\hline Scores & Mean \pm SD & Range & Mean \pm SD & Range \\
\hline FIM- Self-Care (6-42) & $32.93 \pm 11.81$ & $7-42$ & $35.67 \pm 9.60$ & $7-42$ \\
\hline FIM- Sphincter Control (2-14) & $12.22 \pm 3.24$ & $4-14$ & $13.52 \pm 1.57$ & $2-14$ \\
\hline FIM- Mobility (3-21) & $18.58 \pm 4.75$ & $3-21$ & $17.20 \pm 6.03$ & $3-21$ \\
\hline FIM- Locomotion(2-14) & $12.41 \pm 3.04$ & $2-14$ & $10.15 \pm 4.38$ & $2-14$ \\
\hline Wee-FIM- Total Score (18-91) & $76.16 \pm 19.77$ & $28-91$ & $77.10 \pm 19.07$ & $18-91$ \\
\hline Internal Construct Validity (Rasch Analysis) & & & & \\
\hline
\end{tabular}


Table 3. Fit of ACTIVLIM Scale to Rasch Model (After Rescoring)

\begin{tabular}{|c|c|c|c|c|c|}
\hline Items & Location & SE & $\begin{array}{l}\text { Individual } \\
\text { Item Fit } \\
\text { Residual }\end{array}$ & $\begin{array}{c}\text { Chi-Square } \\
\text { Test } \\
\text { Statistics }\end{array}$ & $\mathrm{P}$ \\
\hline Putting On A T-Shirt & -0.648 & 0.193 & -0.513 & 0.630 & 0.427 \\
\hline Washing One's Upper Body & -0.681 & 0.190 & 0.349 & 3.648 & 0.056 \\
\hline Dressing One's Lower Body & -0.005 & 0.172 & -0.829 & 0.138 & 0.710 \\
\hline Taking A Shower & 0.125 & 0.169 & -1.772 & 1.044 & 0.307 \\
\hline Sitting On A Toilet & -1.291 & 0.312 & 0.076 & 0.161 & 0.688 \\
\hline Taking A Bath & 0.487 & 0.164 & -3.238 & 6.795 & 0.009 \\
\hline Walking Downstairs & 0.230 & 0.167 & 0.611 & 2.161 & 0.142 \\
\hline Stepping Out Of A Bath Tub & 0.981 & 0.173 & -1.758 & 1.755 & 0.185 \\
\hline Opening A Door & -2.054 & 0.250 & 1.627 & 0.034 & 0.854 \\
\hline Walking Outdoors On Level Ground & -0.479 & 0.181 & 0.041 & 0.749 & 0.387 \\
\hline Washing One's Face & -2.436 & 0.239 & 0.874 & 1.584 & 0.208 \\
\hline Hanging Up A Jacket On A Hatstand & 0.031 & 0.174 & -0.572 & 2.436 & 0.119 \\
\hline Wiping One's Upper Body & -1.297 & 0.215 & 0.007 & 0.942 & 0.332 \\
\hline Walking Upstairs & 0.994 & 0.192 & -1.066 & 1.385 & 0.239 \\
\hline Carrying A Heavy Load & 2.620 & 0.222 & -0.562 & 2.564 & 0.109 \\
\hline Getting İnto A Car & -1.306 & 0.273 & 0.765 & 1.184 & 0.277 \\
\hline Standing For A Long Time ( \pm 10 Min) & 0.855 & 0.224 & 0.135 & 0.499 & 0.480 \\
\hline Walking More Than 1 Kilometer & 1.769 & 0.208 & -0.293 & 0.100 & 0.752 \\
\hline Closing A Door & -4.679 & 0.426 & 0.156 & 0.755 & 0.385 \\
\hline Hopping On One Foot & 4.087 & 0.285 & -0.390 & 0.279 & 0.597 \\
\hline Putting On A Backpack & 0.521 & 0.221 & -1.536 & 0.749 & 0.387 \\
\hline Running & 2.178 & 0.217 & 1.612 & 0.609 & 0.435 \\
\hline
\end{tabular}


DIF was tested for gender and patient category. Except ACTIVLIM 6 (Taking a bath) that showed DIF by patient category, all remaining items were free of DIF. As shown in Figure 1, adults perceived taking a bath to be more difficult than children across the whole range of the attribute being measured. However, the item was thought to be important for both adults and children, and it was therefore retained in the scale.
All 22 items defined a unidimensional scale of activity limitations since there were no significant differences between observed and expected scores in terms of $p$ values. When the assumption of local independence was examined, there was no pair of items that had a residual correlation of 0.30 or more. Although the mean person score (1.629) is higher than mean item score $(0)$, the final 22 -item scale contains enough items for almost all activity limitation levels as shown Figure 2.

Figure 1. DIF for ACTIVLIM 6 (Taking a Bath) By Patient Category

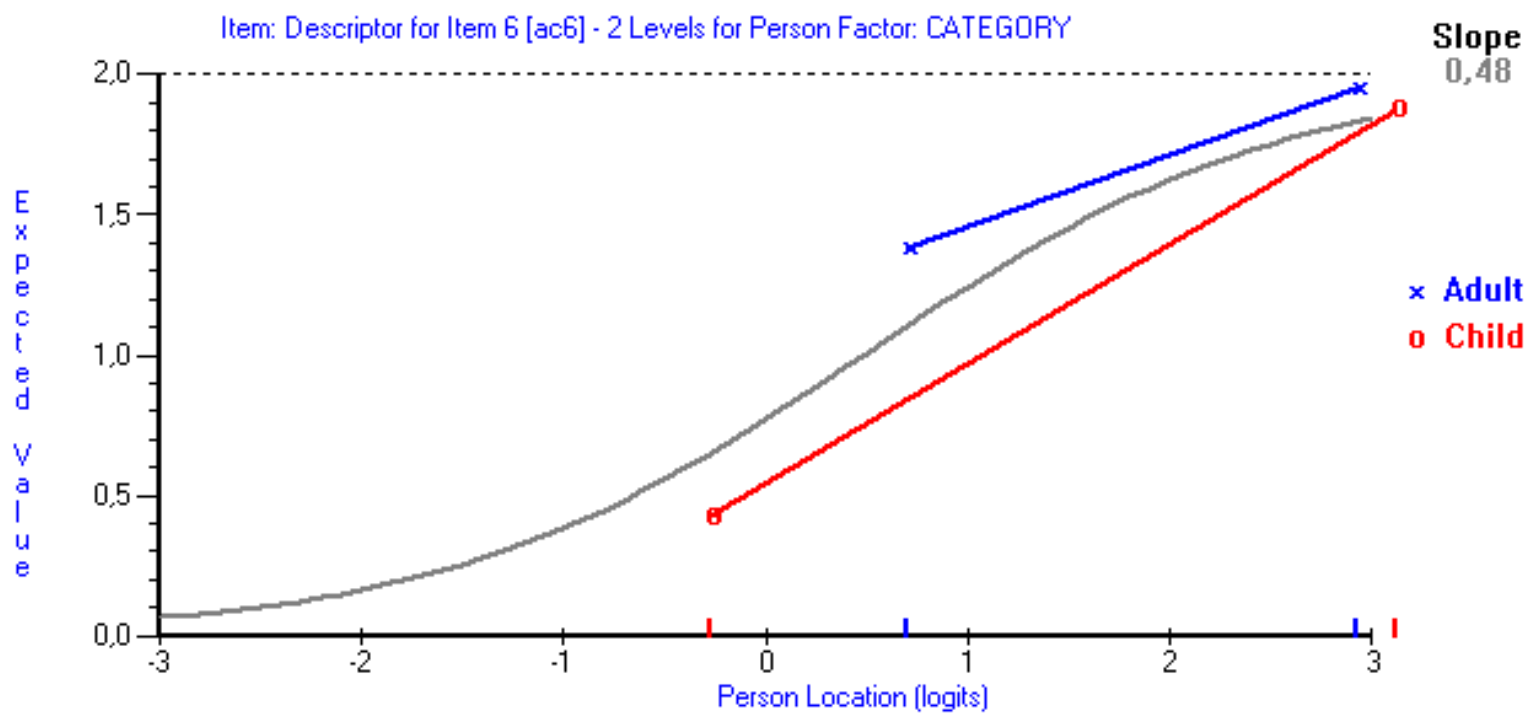

Figure 2. Targetting of ACTIVLIM to Patient Activity Limitation (After Collapsing of Categories)

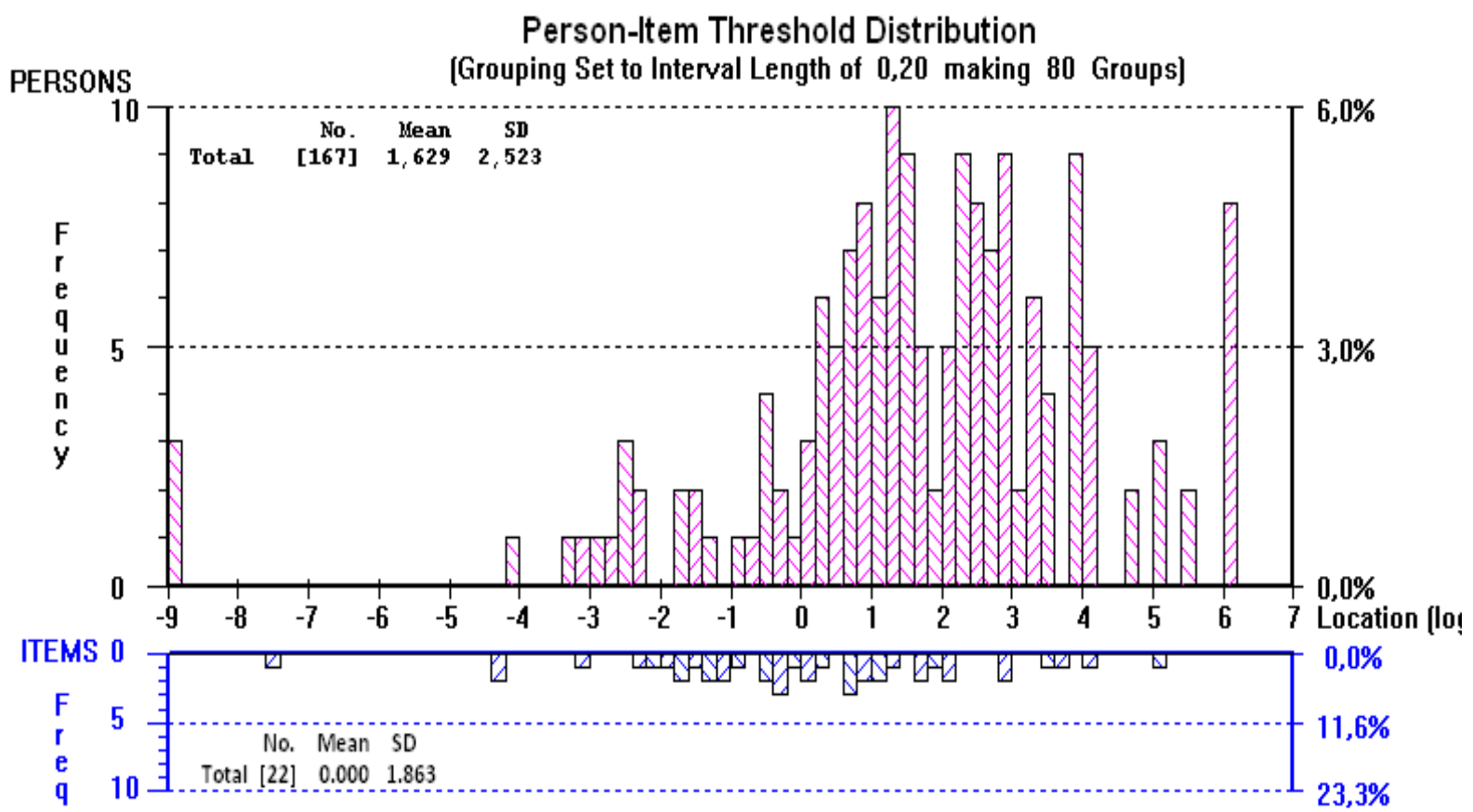


For the reliability all patients were asked to complete the scale for a second time after 15 days so as to assess the test/retest reliability of the ACTIVLIM. When test/retest reliability was examined via DIF by time using Rasch analysis, none of the items showed DIF. When the reliability of the ACTIVLIM was estimated in terms of internal consistency, Cronbach's alpha was found to be 0.94 and the PSI was 0.95 , indicating the ability of the scale to differentiate between 4 groups of patients.

External Construct Validity, the correlation coefficients of the ACTIVLIM and the FIM scores are shown in Table 4. The ACTIVLIM measures showed moderate to strong correlation with the FIM motor scores $(p<0.05)$. The best correlation was identified between the total FIM and self-care subscores with ACTIVLIM scores.

Table 4. Correlation Between ACTIVLIM and FIM/WeeFIM Scores

Activlim

\begin{tabular}{llll}
\hline & & $\mathbf{r}$ & $\mathbf{P}$ \\
\hline Self-Care & FIM & 0.696 & $<0.001^{*}$ \\
\cline { 2 - 4 } & WeeFIM & 0.586 & $<0.001^{*}$ \\
\hline Sphincter Control & FIM & 0.178 & $0.029^{*}$ \\
\cline { 2 - 4 } & WeeFIM & & 0.565 \\
\hline Mobility & FIM & 0.107 & $<0.001^{*}$ \\
\cline { 2 - 4 } & WeeFIM & 0.602 & $<0.05^{*}$ \\
\hline Locomotion & FIM & 0.494 & $<0.001^{*}$ \\
\cline { 2 - 4 } & WeeFIM & 0.687 & $<0.05^{*}$ \\
\hline Total Motor Score & FIM & 0.463 & $<0.001^{*}$ \\
\hline & WeeFIM & 0.692 & $<0.001^{*}$
\end{tabular}

Pearson Correlation Test, ${ }^{*} p<0.05$

\section{DISCUSSION}

According to International Classification of Functioning, Disability and Health - ICF Activity and Participation-describes the person's functional status, including communication, mobility, interpersonal interactions, self-care, learning, applying knowledge, etc. (World Health Organization, 2001). Nowadays to have a complete evaluation of activity limitation and functioning a link to the ICF is needed. Because of the wide variability of activities among cultures an activity limitation assessing scale that has been produced in a culture could not be used in another culture without studying cultural adaptation. Analysis of DIF with the RASCH analyzes by culture is essential. Where DIF is observed, adjustments can be made to allow for cultural differences in outcome measurement (Tennant, Penta, Tesio et al, 2004). On the other hand cross-cultural adaptation of validated outcome instruments has been advocated in order to facilitate their use in international multicenter clinical trials (Ware, Keller, Gandek et al, 1995). So the purpose of this study was to analyze the Turkish verison of Activlim questionnaire in combination with Rasch 
analysis.

The results of our study showed that the adaptation of the Activlim questionnaire to the Turkish language has produced an instrument that has test/retest reliability and demonstrates concurrent and construct validity supporting its use to measure activity limitation for both children and adult NMD patients.

Internal construct validity of Activlim questionnaire was found to be adequate by fit of the data to the Rasch measurement model. The scale was strictly unidimensional and showed no DIF. Only one item (ACTIVLIM 5-Sitting on the toilet) displayed disordered thresholds, collapsed mostly on the category of "easy". Just only one patients answered the question as "impossible". Collapsing on the category of "easy" should be as a consequence that this item is the easiest item for the high functional level of our outpatient study population. But it is obvious that Turkish clinicians should be aware of two type of toilets used in Turkish population when questioning the activity.

The result of no DIF in relation to gender indicates that activity limitation can be experienced similarly in both genders. On the other hand only item 6 (Taking a bath) showed DIF by patient category. Adults perceived taking a bath to be more difficult than children across the whole range of the attribute being measured. Since NMD is a progressive disease, difficulty in doing a specific activity will change over time. Although there is a differential item functioning across age, this item was thought to be important for both adults and children, therefore it was retained in the scale. On the other hand social and cultural differences among the societies as well as families' approaches toward their children affect functional performances of children (Custers, Hoijtink, Van Der Net et al, 2000). In Turkish culture, even the child grows up and has ability to wash his/her body, some Turkish mothers do not allow self-bathing of their children due to safety and hygiene reasons, and help them bathing. Since ACTIVLIM assess the performance of each activity without human or technical assistance Turkish clinicans should be very careful about the accuracy and reliability of the given answer for this activity. This approach by families may cause a bias for this item.

These results suggest that the Activlim questionnaire is a valid measurement tool to evaluate activity limitation for both genders of children and adults with neuromuscular disorders.
ACTIVLIM was found to correlate with FIM in analyses for concurrent validity. Vandervelde also showed a moderate correlation between ACTIVLIM and FIM scores in a sample of NMD patients. Vandervelde mentioned that the motor score of the FIM seems not to be precise enough to distinguish groups of patients in the high levels of the motor score (Vandervelde ve ark, 2007). FIM contains 13 basic motor tasks so ceiling effects have been reported for FIM especially for the high level of patients. On the other hand ACTIVLIM questions the specific activities that has been reported to be difficult in NMD population. So while a patient receive a high score from FIM he/she can receive a low score from ACTIVLIM. Our study also confirmed that even patients who are mostly independent according to FIM motor score could report difficulties with in the activities that are questioned by ACTIVLIM. Although correlation supports the relationship of ACTIVLIM with FIM , the clinician should be aware that FIM motor score and ACTIVLIM measure different aspects of the patient's health (Vandervelde et al, 2007).

NMD can present many different clinical pictures, but muscular weakness is often present and can influence the life of the person. As our study was conducted on an outpatient rehabilitation center, endurance and fatigue is a major problem compared to lack of muscular strength for our patients. So decline in the functional activities was not apparent to the most of the subjects All patients included to the study were mostly ambulated and independent. This distributional difference of the patients might be a limitation of our study.

On the other hand, the wide variability of activities among cultures should be taken into account. There is no validated study that describes the activity patterns of the Turkish population. There can be other culture-specific activities which are difficult for NMD patients not questioned in the ACTIVLIM questionnaire, such as sitting on the floor. These cultural differences in activities necessitate further studies to investigate the similarities between the self-reported version of activity limitations and the limited activities reported by the Activlim questionnaire.

In conclusion, these findings indicate that ACTIVLIM is a reliable and valid self-reported questionnaire that can be used for both children and adults with NMD in Turkish population to assess activity limitation. 


\section{Kaynaklar}

Andrich, D. (1988). Rasch Models for Measurement. London: SAGE Publications

Andrich, D., Sheridan, B., \& Luo, G. (2004). RUMM 2020: A Windows program for analysing item response data according to Rasch Unidimensional Measurement Models. Perth, Western Australia: RUMM Laboratory.

Aybay, C., Erkin, G., Elhan, A. H., Sirzai, H., \& Ozel, S. (2007). ADL assessment of nondisabled Turkish children with the WeeFIM instrument. Am J Phys Med Rehabil, 86(3), 176182.

Beaton, D. E., Bombardier, C., Guillemin, F., \& Ferraz, M. B. (2000). Guidelines for the process of cross-cultural adaptation of self-report measures. Spine, 25(24), 31863191.

Bérard, C., Payan, C., Hodgkinson, I., Fermanian, J., \& MFM Collaborative Study Group. (2005). A motor function measure scale for neuromuscular diseases. Construction and validation study. Neuromusc Disord, 15(7), 463-470.

Cronbach, L. J. (1951). Coefficient alpha and the internal structure of tests. Psychometrika, 16(3), 297-334.

Cup, E. H., Pieterse, A. J., ten Broek Pastoor J.M., Munneke, M., van Engelen, B. G., Hendricks, H. T., et al. (2007). Exercise therapy and other types of physical therapy for patients with neuromuscular diseases: A systematic review. Arch Phys Med Rehabil, 88(11), 1452-1464.

Custers, J. W., Hoijtink, H., van der Net, J., \& Helders, P. J. (2000). Cultural differences in functional status measurement: analyses of person fit according to the Rasch model. Quality of Life Res, 9(5), 571-578.

Elhan, A. H., Öztuna, D., Kutlay, Ş., Küçükdeveci, A. A., \& Tennant, A. (2008). An initial application of computerized adaptive testing (CAT) for measuring disability in patients with low back pain. BMC Musculoskelet Disord, 9(1), 166.

Emery, M. P., Perrier, L. L., \& Acquadro, C. (2005). Patientreported outcome and quality of life instruments database (PROQOLID): frequently asked questions. Health Qual Life Out, 3(1), 12.

Fisher, W. P. (1992). Reliability statistics. Rasch Measurement Transactions, 6(3), 238.

Fisher, W. P. (1993). Measurement-related problems in functional assessment. Am J Occup Ther, 47(4), 331-338.

Hermans, M. C., Faber, C. G., De Baets, M. H., de DieSmulders, C. E., \& Merkies, I. S. (2010). Rasch-built myotonic dystrophy type 1 activity and participation scale (DM1-Activ). Neuromusc Disord, 20(5), 310-318.

Hobart, J. C., Cano, S. J., \& Thompson, A. J. (2010). Effect sizes can be misleading: is it time to change the way we measure change? J Neurol Neurosurg Psychiatry, 81(9), 1044-1048.

Jensen, M. P., Abresch, R. T., \& Carter, G. T. (2005). The reliability and validity of a self-report version of the FIM instrument in persons with neuromuscular disease and chronic pain. Arch Phys Med Rehabil, 86(1), 116-122.

Küçükdeveci, A. A., Yavuzer, G., Elhan, A. H., Sonel, B., \& Tennant, A. (2001). Adaptation of the Functional Independence Measure for use in Turkey. Clin Rehabil, 15(3), 311-319.

Mayhew, A., Cano, S., Scott, E., Eagle, M., Bushby, K., Muntoni, F., et al. (2011). Moving towards meaningful measurement: Rasch analysis of the North Star
Ambulatory Assessment in Duchenne muscular dystrophy. Dev Med Child Neur, 53(6), 535-542.

Merkies, I. S. J., \& Hughes, R. A. C. (2010). The measurement of disease. J Neurol Neurosurg Psychiatry, 81(9), 943943.

Nair, K. S., Vasanth, A., Gourie-Devi, M., Taly, A. B., Rao, S., Gayathri, N., \& et al. (2001). Disabilities in children with Duchenne muscular dystrophy: a profile. J Rehabil Med, 33(4), 147-149.

Öksuz, Ç., Akel, B.S., \& Bumin, G. (2011). Effect of occupational therapy on activity level and occupational peformance in patients with neuromuscular disease. Fizyoterapi Rehabil, 22(3), 231-239.

Raggi, A., \& Leonardi, M. (2009). Assessing activity limitations in patients with neuromuscular diseases: is the ACTIVLIM questionnaire linked to ICF and ICF-CY? Int $J$ Reh Research, 32(2):148-53.

Tennant, A., \& Conaghan, P. G. (2007). The Rasch measurement model in rheumatology: what is it and why use it? When should it be applied, and what should one look for in a Rasch paper? Arthritis Care \& Res, 57(8), 1358-1362.

Tennant, A., Penta, M., Tesio, L., Grimby, G., Thonnard, J. L., Slade, A., \& et al. (2004). Assessing and adjusting for cross-cultural validity of impairment and activity limitation scales through differential item functioning within the framework of the Rasch model: the PRO-ESOR project. Medical Care, 42(1), I37-I48.

Torres, C., Moxley, R. T., \& Griggs, R. C. (1983). Quantitative testing of handgrip strength, myotonia, and fatigue in myotonic dystrophy. J Neur Sci, 60(1), 157-168.

Vandervelde, L., Van den Bergh, P. Y., Goemans, N., \& Thonnard, J. L. (2007). ACTIVLIM: a Rasch-built measure of activity limitations in children and adults with neuromuscular disorders. Neuromusc Disord, 17(6), 459469.

Vandervelde, L., Van den Bergh, P. Y., Renders, A., Goemans, N., \& Thonnard, J. L. (2009). Relationships between motor impairments and activity limitations in patients with neuromuscular disorders. J Neurol Neurosurg Psychiatry, 80(3), 326-332.

Ware, J. E., Keller, S. D., Gandek, B., Brazier, J. E., Sullivan, M., \& IQOLA Project Group. (1995). Evaluating translations of health status questionnaires: Methods from the IQOLA Project. International Journal of Technological Assess Health Care, 11(3), 525-551.

World Health Organization. (2001). International Classification of Functioning, Disability and Health: ICF. Geneva: World Health Organization. 